\title{
The Effect Of Organizational Learning On Organizational Commitment, Job Satisfaction And Work Performance
}

\author{
Raduan Che Rose, Universiti Putra Malaysia, Malaysia \\ Naresh Kumar, Universiti Putra Malaysia, Malaysia \\ Ong Gua Pak, Universiti Putra Malaysia, Malaysia
}

\begin{abstract}
The literature review reveals that there is a relationship between organizational learning organizational commitment, job satisfaction and work performance. However, it is apparent that the integrated relationships between these variables have not been found to be reported. Hence, we examine the relationship among these variables using a sample of public service managers in Malaysia. Organizational learning was found positively related to organizational commitment, job satisfaction, and work performance. Organizational commitment and job satisfaction are also positively related with work performance and these variables partially mediate the relationship between organizational learning and work performance. Implication of the study and suggestions for future research been discussed in this paper.
\end{abstract}

Keywords: organizational learning, organizational commitment, job satisfaction, work performance, public sector, Malaysia

\section{INTRODUCTION}

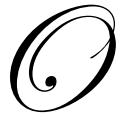

rganizational learning is more of a need than a choice at the present time. It is almost impossible to notice organizations that will admit to ignoring learning, since this would be akin to be accepting the start of its demise (Montes, Moreno and Morales, 2005; Probst and Buchel, 1997). Organizational learning is considered by many a core capability of an effective organization and a key element of a strategy for corporate renewal (Spicer and Sadler-Smith, 2006). Long-term survival, competitiveness and achieving greater performance all depend on the organizations' capacity to match the continuous changes in the environment (Montes et al., 2005). Realizing the importance of organizational learning, it has recently commanded a great deal of attention. As a result, the concept of organizational learning has achieved prominence amongst the ideas, which now influence management studies. Although links between learning and positive work outcomes have often been assumed, there is little empirical evidence to support this perspective (Lopez, Peon and Ordas, 2005). Spicer and Sadler-Smith (2006) contend that the investigation on organizational learning have failed consistently in demonstrating its impact on organizations. They further pointed that the field has suffered from a dearth of empirical evidence to support the assertion that there is a positive relationship between organizational learning and performance based outcomes.

Conversely to Watkins and Marsick (2003), researchers are in the relatively early stages of exploring learning organization constructs and developing measurement approach. These early studies and adoption of learning organization principles in practice have led to growing interactions between organizational learning culture and organizational outcomes (Egan, Yang, and Bartlett, 2004). Although organizational learning theories and practices have been clarified by practitioners and scholars over the past several years, there is much to be explored regarding interaction in organizational learning culture, employees learning and organizational outcomes (Egan $e t$ al., 2004), especially in the public services sector. Noticeably the impact of workplace learning on job satisfaction (Rowden and Conine, 2005; Cropanzano and Byrne, 2001) and organizational commitment (Mohammed and Marquardt, 2007) not been explored adequately in the public sector. 
In many ways, the public service sector is the most natural place to establish a culture of learning. Historically, bureaucratic administrative structures are likely to exist in the public service sector rather than in the commercial world where financial and competitive pressures mitigate against the growth of bureaucracy and assist employees in recalling quite clearly the purposes for the existence of the business and the importance of the organization's survival. Such clarity of purpose has not always been apparent and paramount in the public services sector (Bendell, Boulter \& Kelly, 1994). In the public services sector, it has often been the case that the provision of the service to the public is different than that of a supplier to a customer but rather that of an authority to a subject. The public services sector may not be deliberately belligerent or malevolent, but nonetheless, public sector employees have often found themselves primarily as an agent of the state carrying out an official state purpose, rather than a service to the customers (Bendell et al., 1994). The public services sector is, after all, a monopoly with little concepts of realistic pricing of service against market alternatives and the punitive power is in the hands of the public administrator rather than the customer. It was not that the customer could withdraw his custom but the public service employees could refuse to facilitate it (Bendell et al., 1994). Against this background, the need for organizational learning is clearly important in the public service sector as in the private sector. The belief that the implementation of organizational learning in the public services sector is typically more problematic compared to the private sector has failed to induce sufficient research in years back.

Realizing the deficiency in the literature pertaining to the relationship between organizational learning, organizational commitment, job satisfaction, and work performance in specific to public services sector, an empirical study been carried out to provide new insights to the body of knowledge. In this paper, we report the following: 1) the extent organizational learning explains organizational commitment, job satisfaction and work performance; 2) the extent organizational learning, organizational commitment and job satisfaction explain work performance; 3) the role of organizational commitment and job satisfaction as mediating variables on the relationship between organizational learning and work performance.

\section{REVIEW OF LITERATURE}

In recent years, performance management has come to the fore as organizations seek constantly to optimize their human resources in the face of growing competitive pressures (Suliman, 2001). The general consensus in the learning organization literature is that learning at the organizational level is a prerequisite for successful organizational change and performance (Garvin, 1993; Hendry, 1996). According to Watkins and marsick (1996) learning could enhance the intellectual capabilities of the employees; as such organizations will eventually be better off through having learned employees. Organizational learning can be regarded as a dynamic process of creation, acquisition and integration of knowledge aimed at development of resources and capabilities that contribute to better performance (Chonko et al., 2003; Choe, 2004; Gonzales, 2001; Lopez et al., 2005; Wu and Cavusgil, 2006).

Garver (1996) shows that there is significant positive relationship between measure of learning activities and performance at work indicating higher performers are involved in greater volume of learning activities. Jashapara (1993) reported that learning in an organization have a positive impact on organizational performance. Skerlavaj, Stemberger, Skrinjar and Dimovski (2006) reported from their study that organizational learning has a positive direct impact on performance. The finding from the study conducted by Spicer and Sadler-Smith (2006) in small manufacturing firms also indicates that organizational learning has a positive relationship with financial and non-financial performance of the firms. Similarly many other empirical studies indicated positive relationship between organizational learning and performance outcomes (Correa, Morales, and Pozo (2007) Ellinger et al., 2003; Jimenez and Navarro (2006) Khandekar and Sharma (2006) Power and Waddell (2004) Schroeder, Bates, and Junttila, 2002)

The organizations with the greatest harmony between organizational and individuals goals are those that are sensitive to individuals and provide them with the resources and opportunities for learning and achievement (Rowden and Conine, 2005). Organizations that have made learning, education, and development a priority have seen it pay off through greater profitability and increased employees' job satisfaction (Leslie et al., 1998). Rowden and Conine (2005) examined the impact of workplace learning on job satisfaction in small US commercial banks and reported significant relationship between workplace learning and employees' job satisfaction. According to them, large part of job satisfaction can be attributed to the availability of on the job learning opportunities. Egan et 
al., (2004) also reported that organizational learning culture positively correlates with employees' job satisfaction. Bromfield-Day (2000) reported from her study that there is positive relationship between employee readinesses for self-directed learning with job satisfaction.

In addition to the conceptual and theoretical arguments, there have been a number of empirical studies in support of the relationship between job satisfaction and work performance (Judge et al., 2001; Politis, 2005; Suliman and Iles, 2000; Wilson and Frimpong, 2004; Yousef, 1999). Research shows that employees who experience job satisfaction are more likely to be productive and stay on the job (McNeese-Smith, 1997). The job satisfaction experienced by employees will affect the quality of service they render (Crossman and Abou-Zaki, 2003) and in turn will affect their work performance. The apparent logic is that employees who are satisfied with their job tend to be cooperative, helpful, respectful and considerate, hence deliver an excellent job (Wilson and Frimpong, 2004).

Besides job satisfaction, organizational commitment has been studied extensively during the last three decades (Kontoghiorphes and Bryant, 2004). According to Bartlett (2001), much of the interest in organizational commitment stems from reports of positive consequences on employee's behaviour and desirable work outcomes from organizational commitment. Today, the aspect of organizational commitment is even more important since it is considered as the driving force behind an organization's performance (Kamarul and Raida, 2003). Interests in work related commitment have been sparked by its potential benefits to individuals and organizations (Somers and Birbaum, 2000). It is also an important variable in explaining work-related behaviour and its impact on performance (Benkoff, 1997). Organizational commitment can also be viewed as a dimension of organization effectiveness through work performance and reducing turnover (McDermontt, Laschinger and Shamian, 1996). Many past studies reported positive relationship between organizational commitment and work performance (Arnett, Laverie and McLane 2002; Suliman and Iles, 2000; McNeese-Smith, 1997).

Organizational commitment in relation to job satisfaction has also received considerable attention in past studies and the findings signify positive association between the two variables (Bhuian and Abul-Muhmin, 1997; Yousef, 2002; Yavas and Badur, 1999). Various studies have also discovered positive relation between organizational commitment and job satisfaction and organization's competitiveness (Liou, 1995; Baugh and Roberts, 1994). Indeed organizational commitment and job satisfaction are common variables that affect organizational outcomes (Testa, 2001). Russ and McNeilly (1995) conducted a study to examine the relationship between organizational commitment and job satisfaction using experience, gender and performance as moderators. They reported that experience and performance moderate the relationship between organizational commitment and job satisfaction. Conversely study conducted by Curry, Wakefield, Price and Mueller (1986) reveals no significant relationship between job satisfaction and organizational commitment. Wright (1997) conducted a study to examine the effects of organizational learning and individual learning on job satisfaction and organizational commitment. The results revealed that job satisfaction and organizational commitment strongly influenced by organizational learning. Yeo (2002) proposed that single-loop, double-loop and deutero-loop learning will ultimately result in a positive attitude and work commitment among individuals, hence helping organizations perform better in the long run.

Many studies have been done to test the role of organizational commitment (Suliman, 2002; Norris-Watts and Levy, 2004; Yousef, 2000; Cropanzano et al., 1993) and job satisfaction (Lok and Crawford, 2001; Yousef, 2002; Cropanzano et al., 1993; Chiu and Francesco, 2003) as mediating variables, but to the best of researchers' knowledge, no study been reported specifically on the role of organizational commitment and job satisfaction as mediating variable on the relationship between organizational learning and work performance. Besides, Wright, (1997), Yang et al. (2003), Wang, (2005) have studied the relationship between organizational learning and job related attitude (organizational commitment and job satisfaction) of employees, but these studies did not link these factors to the employees' performance. The lack of attention given to the possible influence of this matter in the pervious studies has highlighted a significant issue that requires further investigation. Hence, we attempted a research with aims to produce an integrated study to cover the gaps identified in the literature and extend earlier research on organizational learning, commitment, job satisfaction and work performance among public service managers in Malaysia. 


\section{RESEARCH METHOD}

The primary data was obtained through a survey using self-administered questionnaire. Items from established instruments were adopted and modified appropriately to suit the objectives of the study. Organizational leaning was measured using 16 items developed by Gomes et al. (2005), 10 item developed by Porter et al. (1974) used to measure organizational commitment, job satisfaction was measured using 12 items from Hackman and Oldham (1975) and work performance was measured using 15 items developed by Suliman (2001). The respondents were asked to respond on a scale ranging from strongly disagree (1) to strongly agree (7). From the analysis, it was identified that the Cronbach alpha of all constructs were between 0.84-0.94, exceeding Nunnally's (1978) recommended threshold value of 0.7. Thus, the instrument used in this study showed a good level in terms of reliability. The last part of the questionnaire collected the demographic information such as respondents' age, gender, educational level, and work experience. The choices are classified and respondents are required to choose the ones that are most applicable to them.

The respondents were chosen by systematic sampling procedure. 500 questionnaires were personally distributed to Administrative and Diplomatic officers at the 28 ministries located in the Federal Territory of Kuala Lumpur and Putrajaya. The Administrative and Diplomatic officers are chosen because they hold almost all the strategic and important positions. Besides, they are the Government's policy formulators and executors. A total of 435 (87\%) fully answered questionnaires were received from the respondents. The Statistical Package for Social Science (SPSS version 14) and Analysis of Moment Structures (AMOS version 6) were used to analyze the collected data.

\section{FINDINGS AND DISCUSSION}

\section{Respondents' background}

Majority of the respondents (64\%) are male. In terms of age distribution, $63 \%$ of the respondents were less than 40 years old, $20 \%$ were between the ages of 41 to 50 years, and $17 \%$ of the respondents were 51 years and above. The wide age range indicates a diverse sample. From the data on educational level, $70 \%$ of the respondents were bachelor's degree holders, $29 \%$ were masters' degree holders, and only $1 \%$ had obtained $\mathrm{PhD}$ qualification. For job category or ranking of the respondents, $52 \%$ are lower level managers, $41 \%$ middle level managers and $7 \%$ top level managers. In term of work experience, $56 \%$ of the respondents had less than 10 years work experience, $8 \%$ had 11 to 15 years work experience, and $36 \%$ had 16 years or more work experience. The following subsection discussed the relationship and mediating effects between the constructs.

\section{Organizational Learning and Work Performance}

From Table 1 and based on Cohen (1988) guideline, there is a positive moderate relationship at the corrected alpha $\leq 0.0125$ level between organizational learning and work performance $(r=.484, n=435, p \leq 0.0001)$. The result indicates that organizational learning has a positive moderate linear relationship with work performance. Improvement in the organizational learning activities among the public service managers increases knowledge, improves capabilities and skills thereby enhance their work performance. The present result supports the findings of earlier studies (Correa, Morales, and Pozo, 2007; Ellinger et al., 2003; Garver, 1996 ; Jashapara, 1993; Jimenez and Navarro, 2006; Khandekar and Sharma, 2006; Power and Waddell, 2004; Schroeder, Bates, and Junttila, 2002; Skerlavaj, Stemberger and Dimovski, 2006; Spicer and Sadler-Smith, 2006). This research further confirms the belief of most managers that organizational learning is a powerful tool to improve performance (Gonzales, 2001). Thus, combined with evidences from the earlier studies linking organizational learning with performance, the findings of this present study support the common and popular argument that learning facilitates behavioural change, increases efficiency and effectiveness of the workforce and facilitates the achievement of organizational goals and objectives. 


\section{Organizational Learning and Organizational Commitment}

There is a high positive relationship at the corrected alpha $\leq 0.0125$ level between organizational learning and organizational commitment $(\mathrm{r}=.561, \mathrm{n}=435, \mathrm{p} \leq 0.0001)$. The result indicates that organizational learning has a positive strong linear relationship with organizational commitment. With improvement in the organizational learning activities, organizational commitment among the public service managers increases. This finding supports the research result of Wright (1997) where organizational commitment was found influencing organizational learning. The present findings also similar to the study conducted by Wang (2003) to examine the relationship among organizational learning culture, job satisfaction, and organizational commitment in native Chinese enterprise settings and the results revealed that organizational learning has significant moderate relationship with organizational commitment. The study conducted by $\mathrm{Ng}$ et al (2006) indicated that opportunity for learning positively effects employees' commitment towards the organization. Yang et al., (2003) examine the dynamic relationships among organizational learning, job satisfaction, and organizational commitment in a Korean context and reported that the three variables concerned were correlated. This result is parallel with the idea proposed by Yeo (2002) that the consequence of organizational learning and the characteristics of a learning organization are antecedents to organizational commitment.

These results support the idea, that, increased organizational commitment is one of the benefits of employee training (Philips, 1997) or learning. Many studies have also reported the positive relationship between training and organizational commitment of the employees (Bartlett, 2001; Grossberg, 2000; Mohammed and Marquardt, 2007). According to $\mathrm{Ng}$ et al. (2006) acquiring knowledge and skills through learning often benefits one's career and is likely to be rewarded by promotions opportunity, higher salary and many other employees' benefits. Therefore, learning is increasingly valued by individuals as it may affect their career attainments and the subjective evaluations of their careers. They further asserted that because the opportunity for learning at work is increasingly desired by employees today, its provision should help elicit employees' perceptions of a quality relational exchange with their employers which will be reciprocated in terms of organizational commitment.

\section{Organizational Learning and Job Satisfaction}

There is a positive high linear relationship at the corrected alpha $\leq 0.0125$ level between organizational learning and job satisfaction $(\mathrm{r}=.551, \mathrm{n}=435, \mathrm{p} \leq 0.0001)$. Improvement in organizational learning activities increases job satisfaction among the public service managers. This finding is in line with research result conducted by Wright (1997), and Egan et al. (2004) where they reported that organizational learning is associated with employees' job satisfaction. Result of the study by Egan et al. (2004) suggests that organizational learning is associated with job satisfaction and although these constructs are highly correlated, they tend to be conceptually distinct. Yang et al. (2003) reported that organizational learning culture acted as a predictive variable to the job satisfaction variable. Wang (2005) reported in his study that organizational learning culture has positive strong relationship with employee job satisfaction. According to Watkins and Marsick (2003), organizations that have prioritized learning and development have found increase in employees' job satisfaction, productivity, and profitability. This statement is further echoed by Rowden and Conine (2005). According to them, organizations that have made learning a priority have seen the payoff through greater employees' job satisfaction. The present finding simply means that the more the managers are involved in the learning activities, the more they are satisfied with their job, the more they are committed to their organizations, and the better their performance in their job.

Table 1: Pearson's Correlation Coefficient between the selected constructs.

\begin{tabular}{lcccccc}
\hline & Mean & $\begin{array}{c}\text { Standard } \\
\text { Deviation }\end{array}$ & OL & OC & JS & WP \\
\hline OL & 5.48 & .597 & 1.000 & & \\
OC & 5.16 & .969 & $.561^{* *}$ & 1.000 & \\
JS & 4.83 & .797 & $.551^{* *}$ & $.736^{* *}$ & 1.000 & $.512^{* *}$ \\
WP & 5.58 & .765 & $.484^{* *}$ & $.535^{* *}$ & .500 \\
\hline
\end{tabular}

Note : ** Correlation is significant at the 0.01 level (2-tailed). 


\section{ORGANIZATIONAL COMMITMENT, JOB SATISFACTION AND WORK PERFORMANCE}

Table 1 indicate a positive strong linear relationship at the corrected alpha $\leq 0.0125$ level between organizational commitment and work performance $(\mathrm{r}=.535, \mathrm{n}=435, \mathrm{p} \leq 0.0001)$. With improvement in the organizational commitment, therefore it increased work performance among the public service managers. Table 1 also indicate a positive moderate linear relationship at the corrected alpha $\leq 0.0125$ level between job satisfaction and work performance $(\mathrm{r}=.512, \mathrm{n}=435, \mathrm{p} \leq 0.0001)$. This clearly indicates that satisfied employees perform better on their job and vice versa. The results of this study provide support to the earlier studies that organizational commitment has positive relationship with managers' performance (e.g. Arnett et al., 2002; Suliman and Iles, 2000). The same results occur for the relationship between job satisfaction and managers performance (e.g. Judge et al., 2001; Politis, 2005; Suliman and Iles, 2000; Wilson and Frimpong, 2004; Yousef, 1999). The findings of this study support the view of Testa (2001) that organizational commitment and job satisfaction affects organizational outcomes such as work performance.

\section{ORGANIZATIONAL COMMITMENT AS MEDIATOR}

The results shown in Table 2 indicate that all the conditions as advocated by Baron and Kenny (1986) were met. The first equation shows that organizational learning is significantly affected by organizational commitment $(\mathrm{t}=14.090 ; \mathrm{p}=0.0001)$. The second equation shows that the organizational learning significantly affects the work performance $(\mathrm{t}=11.517 ; \mathrm{p}=0.0001)$ and the third equation reveals that organizational commitment has a significant unique effect on work performance $(\mathrm{t}=8.103 ; \mathrm{p}=0.0001)$. The beta value in the second equation $(0.484)$ was larger than the beta value in the third equation (0.384). Organizational learning (antecedent) predicts organizational commitment, and organizational commitment in turn predicts the work performance (consequence) of the public service managers. Therefore, in this study it can be concluded that organizational commitment partially mediates the relationship between organizational learning and work performance.

The finding is in line with the study result conducted by Suliman (2002). The findings of the study indicate that organizational commitment plays a partial role as mediator on the relationship between work climate and immediate supervisor rated performance. In other words, organizational commitment does not fully mediate the relationship between work climate and performance. The results indicate that the employees who perceived their work climate positively tend to show higher levels of performance, because they were highly committed. On the other hand, employees who reported less positive perception of the work climate are found to be less committed, and as a result they report lower levels of performance (Suliman, 2002). Yousef (1999) concluded from his study that organizational commitment mediates the relationship between leadership behaviour and job performance. The result of this study in terms of the mediating role of organizational commitment in the relationship between organizational learning and work performance is consistent with the theoretical literature. This finding is consistent and further confirms the results of many studies that one of the most important characteristics of organizational commitment is the mediating role it plays in work organizations (Davy Kinichi \& Scheck, 1997; Thompson and Warner, 1997; Allen and Rush, 1998).

Table 2: Three Steps Separate Regression Equations for Organizational Commitment

\begin{tabular}{lccccc}
\hline Equation & Variable & $\begin{array}{c}\text { Unstandardized } \\
\text { Coefficients } \\
(\mathbf{B})\end{array}$ & $\begin{array}{c}\text { Standardized } \\
\text { Coefficients } \\
\text { (Beta) }\end{array}$ & $\mathbf{t}$ & $\mathbf{p}$ \\
\hline 1 & (Constant) & 6.303 & & .463 & .643 \\
DV: OC & OL & .910 & .561 & 14.090 & .0001 \\
2 & (Constant) & 2.178 & .328 & .0001 \\
DV: WP & OL & .621 & .484 & 11.517 & .0001 \\
3 & (Constant) & 2.128 & .269 & 7.674 & .0001 \\
DV: WP & OL & .345 & .384 & 5.681 & .0001 \\
& OC & .303 & 8.103 & .0001 \\
\hline
\end{tabular}

Note: $\mathrm{DV}=$ Dependent Variable, $\mathrm{OC}=$ Organizational Commitment, $\mathrm{WP}=$ Work performance, $\mathrm{OL}=$ Organizational Learning 


\section{JOB SATISFACTION AS MEDIATOR}

The results from Table 3 indicate that all the conditions as advocated by Baron and Kenny (1986) were met. The result in the first equation indicates that organizational learning significantly affects job satisfaction $(\mathrm{t}=13.757 ; \mathrm{p}=0.0001)$. In the second equation, organizational learning significantly affects work performance $(\mathrm{t}=11.157 ; \mathrm{p}=0.0001)$ and in the third equation job satisfaction has a significant unique effect on work performance $(\mathrm{t}=7.392 ; \mathrm{p}=0.0001)$. The beta value in the second equation (0.484) is larger than the beta value in the third equation (0.351). Therefore, in this study it can be concluded that job satisfaction partially mediates the relationship between organizational learning and work performance. Organizational learning (antecedent) predicts job satisfaction, and job satisfaction in turn predicts the work performance (consequence) of the public service managers. This finding is in line with the results from the study conducted by Lok and Crawford (2001) which indicates that job satisfaction play a partial role as mediator between independent and dependent variables. They reported that a significant proportion of the effects of the antecedents on commitment operated directly on commitment rather than indirectly via their effect on job satisfaction. Chiu and Francisco (2003) reported that job satisfaction mediates the relationship between dispositional traits and turnover intention. The result confirms the role of job satisfaction as a mediating variable in this study. The finding from the study conducted by Carmeli and Freund (2004) indicated that job satisfaction had a mediating role in the relationship between commitment and job performance. Yousef (2002) reported in his study that job satisfaction mediated the influences of role conflict and role ambiguity on various facets of organizational commitment, except continuance commitment and high personal sacrifice. The study conducted by Egan et al. (2004) also revealed that organizational learning activities had an indirect effect on employees' turnover intention and this effect was mediated by job satisfaction. Similar results were also been reported on the role of job satisfaction as mediator by Iverson and Roy (1994), Michaels (1994), and Politis (2005)

Table 3: Three Steps Separate Regression Equations for Job Satisfaction

\begin{tabular}{|c|c|c|c|c|c|}
\hline Equation & Variable & $\begin{array}{c}\text { Unstandardized } \\
\text { Coefficients } \\
\text { (B) } \\
\end{array}$ & $\begin{array}{c}\text { Standardized } \\
\text { Coefficients } \\
\text { (Beta) } \\
\end{array}$ & $\mathbf{t}$ & $\mathbf{p}$ \\
\hline 1 & (Constant) & .797 & & 2.700 & .007 \\
\hline DV: JS & OL & .736 & .551 & 13.757 & .0001 \\
\hline 2 & (Constant) & 2.178 & & 7.328 & .0001 \\
\hline DV: WP & OL & .621 & .484 & 11.517 & .0001 \\
\hline 3 & (Constant) & 1.909 & & 6.753 & .0001 \\
\hline \multirow[t]{2}{*}{ DV: WP } & $\mathrm{OL}$ & .372 & .290 & 6.109 & .0001 \\
\hline & JS & .337 & .351 & 7.392 & .0001 \\
\hline
\end{tabular}

Note: $\mathrm{DV}=$ Dependent Variable, JS= Job Satisfaction, $\mathrm{WP}=$ Work performance, $\mathrm{OL}=$ Organizational Learning

\section{CONCLUSION}

The results of the study suggest that organizational learning plays an important role and significantly contributes to organizational commitment, job satisfaction, and work outcomes of public service managers. Besides, the findings present empirical evidence that organizational commitment and job satisfaction partially mediate the relationship between organizational learning and work performance of the Malaysian public service managers. The result of the present this study contributes to the literature on organizational learning and work outcomes from the Malaysian perspective. More specifically this study enhances and supports the findings of the earlier research regarding the role of organizational commitment and job satisfaction as mediator variables. This study represents original research of these mediating effects.

Public service managers have many roles and responsibilities in the work place, such as managing learning. Strategic organizational initiatives aimed at improving workplace and professional development need to have toplevel support, therefore top management need to have motivation, commitment, knowledge, and ability to create and enhance the learning atmosphere in the organization. Top management need to understand and identify what factors or elements contribute to the effectiveness of organizational learning activities and what factors hinder the learning processes among the public service managers. By doing that, organizations at the same time will be able to achieve 
benefits such as increased organizational commitment, job satisfaction and work performance among the public service managers.

\section{LIMITATION AND SUGGESTION FOR RESEARCH}

One of the limitations of the current study relates to its exclusive use of perceptual measures. It has to be noted that self-reported measures might not exactly or truly reflect the subject of interest. Therefore, future studies should use both objective and perceptual measures of performance, making it possible to compare respondents' perceptions of results against the real findings. This would allow drawing more reliable conclusions about the influence of organizational learning on positive work outcomes. This study only involved Administrative and Diplomatic officers; thus, this study should be replicated to cover a wider sampling frame that is representative of general public service sector. Future research need to explore and validate the relationship between the variables concerned by examining data from other public service schemes such as engineers, teachers, health workers, arm forces and many others. The sample of the study only includes managers who work in the public service sector. Therefore, the outcomes of this study are relevant and may be applicable to the public services sector only or to large organizations that have similar characteristics. The present study attempts to fill the gaps identified in the previous study and expects to provide new insights to the body of knowledge. The outcomes of this study may also instigate and allow others to conduct research on other factors or elements that may possibly affect the relationship between organizational learning and work outcomes.

\section{AUTHOR INFORMATION}

Raduan Che Rose, PhD, is a professor at the Faculty of Economics and Management, Universiti Putra Malaysia. $\mathrm{He}$ received an MSc degree in industrial relations from University of Stirling, Scotland, and a PhD degree in international human resource management from Leeds University Business School, United Kingdom. His primary area of expertise is strategic management of human resources, and his special interests include Japanese-style management, cross-cultural management, managing team effectiveness, and the design of HRM systems to support business imperatives. He may be reached at $\underline{\text { rcr@putra.upm.edu.my. }}$

Naresh Kumar, $\mathrm{PhD}$, is a senior lecturer at the Faculty of Economics and Management, Universiti Putra Malaysia. His primary area of expertise is human resource development, and his research interest includes workplace learning, organizational development, knowledge management, and Human Governance. He has published and presented numerous articles internationally on organizational and management-related studies. He may be reached at naresh@putra.upm.edu.my

Ong Gua Pak is a doctoral candidate at the Graduate School of Management, Universiti Putra Malaysia. His areas of research are workplace learning and organizational behavior.

\section{REFERENCES}

1. Allen, T. and Rush, M. (1998). The effect of organizational citizenship behavior on performance judgments: a field study and a laboratory experiment. Journal of Applied Psychology. 83(2), 247-260.

2. Arnett, D.B., Laverie, D.A. and McLane, C. (2002). Using job satisfaction and pride as internal-marketing tools. Cornell Hotel and Restaurant Administration Quarterly, 43(2), 87-96.

3. Bartleet, K.R. (2001). The relationship between training and organizational commitment: a study in the health care field. Human Resource Development Quarterly._12(4), 335-352.

4. Baron, R. and Kenny, D. (1986). The moderator-mediator variable distinction in social psychological research: conceptual, strategic, and statistical considerations. Journal of Personality and Social Psychology. 51(6), 1173-1182.

5. Benkoff, B. (1997). Ignoring commitment is costly: new approaches establish the missing link between commitment and performance. Human Relations. 50, 701-726.

6. Bendell, T., Boulter, L, and Kelly, J. (1994). Implementing quality in the public sector. London: Pitman Publishing. 
7. Bhuian, S.N. and Abdul-Muhmin, A.G. (1997). Job satisfaction and organizational commitment among "guest-worker" salesforces: the case of Saudi Arabia. Journal of Global Marketing. 10(3), 27-44.

8. Bromfield-Day, D. (2000). Employee readiness for self-directed learning and selected organizational variables as predictors of job performance. Unpublished doctoral dissertation, University of Southern Mississippi.

9. Carmeli, A. and Freund, A. (2004). Work commitment, job satisfaction, and job performance: an empirical investigation. International Journal of Organization Theory and Behavior. 7(3), 289-309.

10. Chiu, R.K. and Francesco, A.M. (2003). Dispositional traits and turnover intention: examining the mediating role of job satisfaction and affective commitment. International Journal of Manpower. 24(3), 284-298.

11. Choe, J. M.,(2004). The relationships among management accounting information, organizational learning and production performance. Journal of Strategic Information Systems. 13, 61-85.

12. Chonko, L.B., Dubinsky, A.J., Jones, E. and Roberts, J.A. (2003). Organizational and individual learning in the sales force: an agenda for sales research. Journal of Business Research. 56(12), 935-946.

13. Correa, F.A.A., Morales, V.J.G. and Pozo, E.C. (2007). Leadership and organizational learning's role on innovation and performance: lessons from Spain. Industrial Marketing Management. 36, 349-359.

14. Cropanzano, R. and Byrne, Z. (2001). When it's time to stop writing policies: an inquiry into procedural injustice. Human Resource Management. 11(1), 31-54.

15. Crossman, A. and Abou-Zaki, B. (2003). Job satisfaction and employee performance of Labanese banking staff. Journal of Managerial Psychology. 18(4), 368-376.

16. Curry, J.P., Wakefield, D.S., Price, J.L., and Mueller, C.W. (1986). On the casual ordering on job satisfaction and organizational commitment. Academy of Management Journal. 29(4), 847-858.

17. Davy, J., Kinichi, A. and Scheck, C. (1997). A test of job security's direct and mediated effects on withdrawal cognitions. Journal of Organisational Behaviour. 18, 323-349.

18. Egan, T.M., Yang, B., and Bartlett, K.R. (2004). The effects of organizational learning culture and job satisfaction on motivation to transfer learning and turnover intention. Human Resource Development Quarterly.15(3), 279-301.

19. Ellinger, A.D., Elinger, A.E., Yang, B. and Howton, S.W. (2003). Making the business case for the learning organization concept: the problem and the solution. Advances in Developing Human Resources. 5(2), 163-172.

20. Garver, C.R. (1996). Organizational learning climate, self-directed learner characteristics, and job performance among the police officers. Unpublished doctorial dissertation. The Pennsylvania State University.

21. Garvin, D.A. (1993). Building a learning organization. Harvard Business Review. July-August, 78-91.

22. Gomez, P.J., Lorente, J.C., and Cabrera, R.V. (2005). Organizational learning capability: a proposal of measurement. Journal of Business Research. 58, 715-725.

23. Gonzales, J.J. (2001). Merging organizational learning with learning theory - a task for the $21^{\text {st }}$ Century. J.Struct. Learn. \& Intel. Sys. 14, 355-369.

24. Grossberg, A.J. (2000). The effects of formal training on employment duration. Industrial Relations. 39(4), 578-588.

25. Hackman, R.J. and Oldham, G.R. (1975). Development of the job diagnostic survey. Journal of Applied Psychology. 60(2), 159-171.

26. Hendry, C. (1996). Understanding and creating while organizational change through learning theory. Human Relations. 49(5), 621-641.

27. Iverson, R.D. and Roy, P. (1994). A causal model of behavioural commitment: evidence from a study of Australian blue-collar employees. Journal of Management . 20(1), 15-41.

28. Jashapara, A.(1993).The competitive learning organization: a quest for the holly grail. Management Decision. 31(8), 52-62.

29. Jimenez, D.J. and Navarro, J.G.C. (2006). The performance effect of organizational learning and market orientation. Industrial Marketing Management. 36(6), 694-708.

30. Judge, T.A., Thoresen, C.J., Bono, J.E. and Patton, G.K. (2001). The job satisfaction-job performance relationship: a qualitative and quantitative review. Psychological Bulletin. 127(3), 376-407. 
31. Kamarul, Z. A. and Raida, A.B. (2003). The association between training and organizational commitment among the white-collar workers in Malaysia. International Journal of Training and Development. 7(3), 166-185.

32. Khandekar, A. and Sharma, A. (2006). Organizational learning and performance: understanding Indian scenario in present global context. Education and Training. 48 (8/9), 682-692.

33. Kontoghiorphes, C. and Bryant, N. (2004). Exploring employee commitment in a service organization in the health care insurance industry. Organizational Development Journal. 22(3), 59-74.

34. Lok, P. and Crawford, J. (2001). Antecedents of organizational commitment and the mediating role of job satisfaction. Journal of Management Psychology. 16(8), 594-613.

35. Liou, K.T. (1995). Understanding employee commitment in a public organization: a study of juvenile detention center. International Journal of Public Administration. 18(8), 1269-1295.

36. Lopez, S.P., Peon, J.M.M. and Ordas, C.J.V. (2005). Organizational learning as a determining factor in business performance. The Learning Organization. 12(3), 227-245.

37. McDermott, K., Laschinger, H.K.S. and Shamian, J. (1996). Work empowerment and organizational commitment. Nursing Management. 27, 44-47.

38. McNeese-Smith, D.K. (1997). The influence of manager behaviour on nurses' job satisfaction, productivity and commitment. Journal of Nursing Administration. 27, 47-55.

39. Michaels, P. (1994). An expanded conceptual framework on organizational commitment and job satisfaction for sales force management. Journal of Business and Society. 7(1), 42-67.

40. Mohammed, A.S. A-E. and Marquardt, M.J. (2007). Relationship between employees, beliefs regarding training benefits and employees' organizational commitment in a petroleum company in the State of Qatar. International Journal of Training and Development. 11(1), 49-70.

41. Montes, F.J.L., Moreno, A.R., and Morales, V.G. (2005). Influence of leadership support and teamwork cohesion on organizational learning, innovation and performance: an empirical examination. Technovation. 25, 1159-1172.

42. Nannully, J. (1978). Psychometric theory. (2 $2^{\text {nd }}$ ed.), New York: McGraw-Hill.

43. Ng, T.W.H., Butts, M.M., Vandenberg, R.J., DeJoy, D.M. and Wilson, M.G. (2006). Effects of management communication, opportunity for learning, and work schedule flexibility on organizational commitment. Journal of Vocational Behaviour. 68, 474-489.

44. Norris-Watts, C., and Levy, P.E. (2004). The mediating role of affective commitment in the relation of the feedback environment to work outcomes. Journal of Vocational Behaviour. 65, 351-365.

45. Politis, J.D (2005). Self-leadership behavioural-focused strategies and team performance: the mediating influence of job satisfaction. Leadership and Organization Journal. 27(3), 203-216.

46. Porter, L., Steers, R., Mowday, R., and Boulian, P. (1974). Organizational commitment, job satisfaction and turnover among psychiatric technicians. Journal of Applied Psychology. 59, 603-609.

47. Power, J. and Waddell, D. (2004). The link between self-managed work teams and learning organizations using performance indicators. The Learning Organization. 11(2/3), 244-259.

48. Probst, G.J.B. and Buchel, B.S.T. (1997). Organizational learning: the competitive advantage of the future. New York: Prentice Hall.

49. Rowden, R.W. and Conine Jr. (2005). The impact of workplace learning on job satisfaction in small US commercial banks. Journal of Workplace Learning.17(4), 215-230.

50. Phillips, J.J. (1997). Handbook of training evaluation and measurement methods. Houston: Gulf Publishing.

51. Schroeder, R.G., Bates, K.A. and Junttila, M.A. (2002). A resource-based view of manufacturing strategy and the relationship to manufacturing performance. Strategic Management Journal. 23, 105-117.

52. Skerlavaj, M., Stemberger, M.I., Skrinjar, R. and Dimovski, V. (2006). Organizational learning culture- the missing link between business process change and organizational performance. International Journal Production Economics. 106, 346-367.

53. Suliman, A.M.T. (2001). Work performance: is it one thing or many things? The multidimensionality of performance in a Middle Eastern context. International Journal of Human Resource Management. 12(6), 1049-1061.

54. Suliman, A.M.T. (2002). The mediating role of organizational commitment in work climate-performance relationship. Journal of Management Development. 21(3), 170-183. 
55. Suliman, A.M.T. and Iles, P. (2000). Is continuance commitment beneficial to organizations? Commitmentperformance relationship: a new look. Journal of Managerial Psychology. 15(5), 407-426.

56. Spicer, D.P. and Sadler-Smith, E. (2006). Organizational learning in smaller manufacturing firms. International Small Business Journal. 24(2), 133-158.

57. Somers, M.J. and Birnbaum, D. (2000). Exploring the relationship between commitment profiles and work attitudes, employees withdrawal and job performance. Public Personnel Management. 29(3), 353-364.

58. Thompson, H. and Werner, J. (1997). The impact of role conflict/facilitation on core and discretionary behaviours: testing a mediated model. Journal of Management. 23(4), 583-601.

59. Testa, M.R. (2001). Organizational commitment, job satisfaction, and effort in the service environment. The Journal of Psychology. 135(2), 226-236.

60. Watkins, K.E., Marsick, V.J. (2003), Demonstrating the value of an organization's learning culture: the dimensions of the learning organization questionnaire, Advances in Developing Human Resources, 5 (2):132-51.

61. Wang, X. (2005). Relationship among organizational learning culture, job satisfaction, and organizational commitment in Chinese state-owned and privately-owned enterprises. Unpublished doctorial dissertation, University of Minnesota.

62. Wilson, A. and Frimpong, J. (2004). A reconceptualisation of the satisfaction-service performance thesis. Journal of Service Marketing. 18(6), 471-481.

63. Wright, D.L. (1997). The effects of organizational and individual learning on job satisfaction and organizational commitment. Unpublished doctorial dissertation, Louisiana Tech University.

64. Wu, F. and Cavusgil, S.T. (2006). Organizational learning and joint value creation in interfirm relationships. Journal of Business Research. 59, 81-89.

65. Yang, B., Lim, T., McLean, G.N. (2003), "Impacts of organization's learning culture on job satisfaction and organizational commitment: a structural equation modeling approach", in Akaraborworn, C.T., OsmanGani, A.M., McLean, G.N. (Eds),Human Resource Development in Asia: National Policy Perspectives, National Institute of Development Administration and Academy of Human Resource Development, Bangkok, pp.361-9.

66. Yavas, U. and Badur, M. (1999). Satisfaction among expatriate managers: correlates and consequences. Career Development International. 4(5), 261-269.

67. Yeo, R. (2002). Learning within organizations: linking the theoretical and empirical perspectives. Journal of Workplace Learning. 14(3), 109-122.

68. Yousef, D.A. (1999). Organizational commitment: a mediator of the relationships of leadership behaviour with job satisfaction and performance in a non-western country. Journal of Managerial Psychology. 15(1), 6-28.

69. Yousef, D.A. (2002). Job satisfaction as a mediator of the relationship between role stressors and organizational commitment. Journal of Managerial Psychology. 17(4), 250-266. 
NOTES 